\title{
The Implication of Aberrant GM-CSF Expression in Decidual Cells in the Pathogenesis of Preeclampsia
}

\author{
S. Joseph Huang, ${ }^{*}$ Ana C. Zenclussen, ${ }^{\dagger}$ \\ Chie-Pein Chen, ${ }^{\mp}$ Murat Basar, ${ }^{* \S}$ Hui Yang, ${ }^{*}$ \\ Felice Arcuri," Min Li, ${ }^{*}$ Erdogan Kocamaz, ${ }^{*, * *}$ \\ Lynn Buchwalder, ${ }^{*}$ Mizanur Rahman, ${ }^{*}$ \\ Umit Kayisli, ${ }^{*}$ Frederick Schatz, ${ }^{*}$ Paolo Toti, ${ }^{\|}$ \\ and Charles J. Lockwood* \\ From the Department of Obstetrics, Gynecology, and \\ Reproductive Sciences," Yale University, New Haven, Connecticut; \\ the Department of Experimental Obstetrics and Gynecology, ${ }^{\dagger}$ \\ Otto-von-Guericke-University, Magdeburg, Germany; the Division \\ of High Risk Pregnancy, ${ }^{\ddagger}$ Mackay Memorial Hospital, Taipei, \\ Taiwan; the Cerrahpasa Medical Faculty, Department of \\ Histology and Embryology, ${ }^{\S}$ University of Istanbul, Istanbul, \\ Turkey; the Department of Obstetrics and Gynecology, "Renji \\ Hospital, Shanghai Jiao Tong University, Shanghai, China; the \\ Department of Pathology," Siena University, Siena, Italy; and the \\ Department of Histology and Embryology, * University of \\ Pamukkale, Medical Faculty Denizli, Turkey
}

Preeclampsia is characterized by an exaggerated systemic inflammatory state as well as shallow placentation. In the decidual implantation site, preeclampsia is accompanied by an excessive number of both macrophages and dendritic cells as well as their recruiting chemokines, which have been implicated in the impairment of endovascular trophoblast invasion. Granulocyte-macrophage colony-stimulating factor is known to regulate the differentiation of both macrophages and dendritic cells, prompting both in vivo and in vitro evaluation of granulocyte-macrophage colony-stimulating factor expression in human decidua as well as in a mouse model of preeclampsia. This study revealed increased granulocyte-macrophage colony-stimulating factor expression levels in preeclamptic decidua. Moreover, both tumor necrosis factor- $\alpha$ and interleukin-1 $\beta$, cytokines that are implicated in the genesis of preeclampsia, markedly up-regulated granulocyte-macrophage colony-stimulating factor production in cultured first-trimester human decidual cells. The conditioned media of these cultures promoted the differentiation of both macrophages and dendritic cells from a monocyte precursor. Evaluation of a murine model of preeclampsia revealed that the decidua of af- fected animals displayed higher levels of immunoreactive granulocyte-macrophage colony-stimulating factor as well as increased numbers of both macrophages and dendritic cells when compared to control animals. Because granulocyte-macrophage colony-stimulating factor is a potent inducer of differentiation and activation of both macrophages and dendritic cells, these findings suggest that this factor plays a crucial role in the pathogenesis of preeclampsia. (Am J Patbol 2010, 177:2472-2482; DOI: 10.2353/ajpath.2010.091247)

Implanting human blastocyst-derived extravillous cytotrophoblasts penetrate an underlying decidua comprised primarily of resident decidual cells (50\%) and an assortment of immune cells. The extravillous cytotrophoblasts then invade the inner myometrium during the period of placentation. As they traverse the decidua, extravillous cytotrophoblasts enter and transform spiral arteries and arterioles into low-resistance, high-capacity vessels that increase utero-placental blood flow to the developing fetal-placental unit. In many cases of preeclampsia, a multisystem disorder that is the single leading cause of maternal and fetal morbidity and mortality worldwide, ${ }^{1}$ shallow decidual invasion by extravillous cytotrophoblasts leads to incomplete vascular remodeling. The resulting decreased utero-placental blood flow causes the placenta to become relatively hypoxic ${ }^{2}$ and secretes an array of antiangiogenic factors, ${ }^{2}$ placental debris, reactive oxygen species, and proinflammatory cytokines into the maternal circulation. The resulting systemic endothelial cell activation and vascular damage leads to vaso-

Supported by National Institute of Child Health and Development, National Institutes of Health 5R01HD056123-02 (S. J. Huang), and March of Dime 21-FY05-1249 grants (C. J. Lockwood).

Accepted for publication July 21, 2010

None of the authors disclose any conflict of interests.

Supplemental material for this article can be found on http://ajp. amjpathol.org.

Address reprint requests to S. Joseph Huang, M.D., Ph.D., Department of Obstetrics, Gynecology, and Reproductive Sciences, Yale University School of Medicine, 333 Cedar Street, P.O. Box 208063, New Haven, CT 06520-8063. E-mail: joseph.huang@yale.edu. 
spasm, hypertension, increased platelet turnover, and a characteristic renal lesion with proteinuria. ${ }^{3}$

Decidual immune cells promote extravillous cytotrophoblast invasion and confer immune tolerance of the semiallogeneic embryo-fetal transplant. ${ }^{4}$ By contrast, preeclampsia-related impaired extravillous cytotrophoblast invasion is associated with local immune maladaptation reflecting in part excess infiltration and differentiation of leukocytes that mediate innate and adaptive immunity. ${ }^{3,5}$ In this regard, we ${ }^{6}$ and others ${ }^{7}$ observed that decidua from preeclamptic women contains an excess of macrophages, as well as immature and mature dendritic cells. ${ }^{8}$ In the implantation site of uncomplicated gestations, macrophages may modulate extravillous cytotrophoblast invasion secondary to phagocytosis of apoptotic cells and remodeling of the decidua. ${ }^{9}$ However, in preeclampsia, tumor necrosis factor- $\alpha$ (TNF- $\alpha$ ) derived from excess decidual macrophages is implicated in impairing extravillous cytotrophoblast invasion by inducing extravillous cytotrophoblast apoptosis and by enhanced synthesis of plasminogen activator inhibitor-1, which inhibits urokinase plasminogen activator expressed at the leading edge of trophoblast invasion. Unlike the excess of macrophages, dendritic cell infiltration in the decidua from preeclamptic women does not appear to impede extravillous cytotrophoblast invasion directly. ${ }^{8}$ Alternatively, in view of the strong involvement of dendritic cells in inducing immune tolerance in other systems, the excess of dendritic cells in term decidua may account for the high incidence of subsequent immune tolerance of the allogeneic placenta with improved extravillous cytotrophoblast invasion and reduced recurrence and/or severity of preeclampsia in subsequent pregnancies.

Colony-stimulating factors (CSFs) are secreted by diverse cell types and mediate unique and pleiotropic functions. ${ }^{10}$ Among CSF family members, granulocyte-monocyte (GM)-CSF affects survival and growth of myeloid leukocytes. Monocytes migrate into tissues in response to inflammatory stimuli and then differentiate into either macrophages or immature dendritic cells. ${ }^{11}$ In vitro studies indicate that incubation with macrophage (M)-CSF and GM-CSF transform monocytes to macrophages, whereas GM-CSF and interleukin (IL)-4 convert monocytes into immature dendritic cells. ${ }^{12}$ Mature antigenloaded dendritic cells migrate into peripheral lymph nodes and activate naïve T-lymphocytes. These activated T-lymphocytes are then recruited back to the peripheral site of inflammation to mediate adaptive immune response.

In the nonpregnant human endometrium, GM-CSF is synthesized primarily by luminal and glandular epithelial cells ${ }^{13-15}$ with a peak in GM-CSF mRNA levels observed during the "window of implantation." In contrast, the mRNA for the GM-CSF receptor is localized to endothelial cells of spiral arteries. ${ }^{16}$ Moreover, GM-CSF is a growth factor for trophoblast and other placental cells. ${ }^{17}$

There are contradictory reports as to whether GM-CSF levels are elevated in the maternal serum and placenta of preeclamptic patients. ${ }^{18,19}$ Surprisingly, GM-CSF expression has not been assessed in decidua from preeclamptic women, the crucial site of impaired extravillous cy- totrophoblast invasion associated with local immune maladaptation. The critical contribution of macrophages and dendritic cells to preeclampsia-related immune maladaptation at the implantation site taken together with the importance of GM-CSF in determining the local macrophage and dendritic cell population emphasized the need to address placental bed GM-CSF involvement in the pathogenesis of preeclampsia. Major obstacles in carrying out the research into the pathogenesis of preeclampsia include: i) the late onset of clinical manifestations (usually in the third trimester), whereas the placental pathogenesis occurs early in pregnancy; and ii) ethical proscriptions regarding prospective obtainment of human tissues compounded by the absence of unambiguous early markers that predict those women who will go on to develop preeclampsia. Therefore, the current study approached this question by using an integrated threetiered approach in which: i) In situ studies compared the cellular immunolocalization of GM-CSF in the major cell types of maternal-fetal interface in preeclamptic versus gestational age-matched control decidua; ii) In vitro studies assessed the effects of preeclampsia-related proinflammatory cytokines on the regulation of GM-CSF expression in monolayer leukocyte-free first trimester decidual cells, ${ }^{20}$ the predominant cell type encountered by invading extravillous cytotrophoblasts; and iii) in vivo studies with a mouse model of preeclampsia was used to correlate decidual macrophage and dendritic cell infiltration with GM-CSF expression in decidual cells and the occurrence of preeclampsia-like symptoms.

\section{Materials and Methods}

\section{Patients' Specimen Collections}

Placental specimens were obtained from patients with preeclampsia defined as the occurrence of elevated blood pressure $(>140 / 90 \mathrm{~mm} \mathrm{Hg}$ ) and proteinuria $(>+1$ on a urine dip stick) identified on two occasions six hours apart after 20 weeks of gestation ${ }^{21}$ in the absence of signs and symptoms of chorioamnionitis or chronic villitis. All cases (37-40 weeks) were delivered by Cesarean section without labor and specimens obtained under Institutional Review Board from the Mackay Memorial Hospital, Taipei, Taiwan and the University of Siena, Siena, Italy. In Mackay Memorial Hospital, decidual tissues from placental bed biopsies were obtained by sharp dissection of the decidua basalis about 1 to $2 \mathrm{~cm}$ in diameter from the maternal surface of placenta around cord insertion area following Caesarean delivery. Microscopic examination after hematoxylin and eosin stain confirmed the identity of each issue before use. The incidence of preeclampsia accompanied with intrauterine growth restriction in our study population was 25\% (2/8). Gestational age-matched controls without labor and signs of preeclampsia were also obtained after Cesarean delivery. In Siena University, multiple full-thickness placental blocks were taken and histologically examined. For each specimen, a block that best represented the maternal decidua was selected for immunohistochem- 
istry. Tissues were snap-frozen in liquid nitrogen or fixed in $10 \%$ buffered neutral formalin and embedded in paraffin.

\section{Mouse Model of Preeclampsia}

Female BALB/c mice and C57BL/6 male were obtained from BgVV or Harlan Winkelmann, Germany and maintained in a barrier animal facility with food and water ad libitum and 12-hour light cycles. Animal care and experimental procedures were approved by the German ministry and followed according to the institutional guidelines (LaGeSo, Berlin, Germany; Reg 039/03). C57/BL6-mated $\mathrm{BALB} / \mathrm{c}$ females received either $3 \times 10^{7}$ Th1-like splenocytes or PBS on gestational days 10 and 12 [preeclampsia $(n=9)$ and control $(n=13)]^{22,23}$ Th1-like cell transfer predisposed fetal rejection (Supplemental Figure $1 \mathrm{~A}$ at http://ajp.amjpathol.org). Blood pressure was measured by a tail cuff method as previously described. ${ }^{22,23}$ On gestational day 14, the mice were sacrificed. Placentae were prepared in paraffin blocks for immunohistochemistry and in Trizol for total RNA isolation.

\section{Immunohistochemistry}

\section{Human Tissues}

Sections $(4 \mu \mathrm{m})$ of formalin-fixed paraffin-embedded placenta and attached fetal membranes were cut, deparaffinized, rehydrated, and washed in Tris-buffered saline [TBS: $20 \mathrm{mmol} / \mathrm{L}$ Tris- $\mathrm{HCl}, 150 \mathrm{mmol} / \mathrm{L} \mathrm{NaCl}(\mathrm{pH}$ 7.6)]. TBS was used for all subsequent washes and for antibody. Antigen retrieval was carried out by incubating sections in Target Retrieval Solution High pH (DAKO, Copenhagen, Denmark), in a microwave oven at 750 Watts for 15 minutes. Sections were subsequently rinsed in $3 \%$ hydrogen peroxide to block endogenous peroxidase and incubated overnight at $4^{\circ} \mathrm{C}$ with monoclonal antibodies against GM-CSF (R\&D Systems, Minneapolis, $\mathrm{MN}$ ), vimentin, and cytokeratin (DAKO) diluted in TBS. Slides were then washed three times with TBS for 5 minutes and incubated with the universal labeled streptavidin biotin (LSAB) Kit (DAKO). After washing three times for 5 minutes in TBS, sections were stained with 3,3'diaminobenzidine tetrahydrochloride (Sigma-Aldrich, St. Louis, MO) as chromogen substrate and counterstained with Harris hematoxylin (Sigma-Aldrich). The reaction was stopped by washing the sections in distilled water, and slides were mounted and observed under a light microscope. Staining specificity was tested by substituting monoclonal IgG isotype of anti-GM-CSF antibody (R\&D Systems) for the primary antibody. In preeclampsia-associated and control placentae, positive immunostaining for GM-CSF was detected in virtually all of the decidual cells. This observation mandated immunostaining for GM-CSF to be quantified semiquantitatively on the basis of staining intensity. This was carried out by a single observer blinded to the specimens using a threegrade scale, ranging from the most intense staining $(++)$ to the weaker (moderate staining: + ; weak staining: $0 /+$ ).
For each slide, the whole decidua was assessed. Areas were chosen at $\times 25$ magnification and each of them was examined in-deep for semiquantitative evaluation at $\times 200$ magnification. A minimum of twelve fields were examined for each slide.

\section{Mouse Tissues}

Immunohistochemistry was performed as previously described $^{24}$ using rat monoclonal anti-GM-CSF (Santa Cruz Biotechnology, Inc., Santa Cruz, CA), rabbit polyclonal anti-GRP94 (Imgenex, San Diego, CA), and rat monoclonal antibody to macrophages (Abcam Inc. Cambridge, MA). Briefly, $5 \mu \mathrm{m}$ formalin-fixed paraffin-embedded sections were deparaffinized in xylene and rehydrated through a descending series of ethanol. Antigen retrieval was then performed by boiling the slides in citrate buffer (10 mmol/L; pH 6.0) for 15 minutes for GRP94 and macrophage surface marker, and by incubating with trypsin for 10 minutes for GM-CSF. The staining was performed according to the manufacturer's instruction for Consolidate Immunohistochemistry DAB Kit (BioGenex, San Ramon, CA) for GM-CSF and macrophages. For GRP94 antibody, Super Sensitive Immunohistochemistry Detection System for Automation Kit (BioGenex, San Ramon, CA) and Rabbit Link HRP/DAB were used. After antigen retrieval, slides were incubated with peroxide for 5 minutes at room temperature to quench endogenous staining according to the manufacturer's instructions. The slides were then incubated with Power Block Reagent for 5 minutes at room temperature in a humidified chamber. Excess serum was then removed, and serial sections were incubated with anti-GM-CSF at 1:50 dilution in TBS, anti-GRP94 at 1:50 dilution in TBS, and rat monoclonal antibody to macrophages at 1:150 dilution in TBS overnight in a humidified chamber at $4^{\circ} \mathrm{C}$. Nonspecific rabbit IgG polyclonal and rat IgG isotype antibodies were used at the same concentrations as the primary antibodies for negative controls. The slides were washed $\times 3$ in TBS for 5 minutes and then incubated with secondary antibody for 20 minutes at room temperature. After washing in TBS, slides were incubated with streptavidin-horseradish peroxidase for 20 minutes at room temperature to detect the antigen-antibody complex using 3,3-diaminobenzidine tetrahydrochloride dehydrate as chromogen. Slides were then counterstained with hematoxylin and mounted with Permount (Fisher Chemicals, Springfield, NJ).

The intensity of immunostaining was semiquantitatively evaluated using HSCORE analysis. The intensity of immunostaining was categorized into the following scores: 0 (no staining), 1 (weak staining), 2 (moderate staining), and 3 (intense staining). An HSCORE value was derived for each specimen by calculating the sum of the percentage of cells that stained at each intensity category multiplied by its respective intensity score, using the formula HSCORE $=\Sigma \mathrm{Pi}(i+\mathrm{I})$, where $i$ represents the intensity score and $\mathrm{Pi}$ is the corresponding percentage of cells. ${ }^{25}$ For each slide, five different fields were evaluated at $\times 400$ magnification. HSCORE evaluation was performed 
independently by two investigators blinded to the source of the samples; the average score of both was then used.

\section{Immunofluorescent Staining}

Decidual tissues from placental bed biopsies were collected under Institutional Review Board approval and snap frozen in liquid nitrogen for cryosections $(5 \mu \mathrm{m}$ in thickness). Tissue was confirmed by hematoxylin and eosin stain. Sections were air-dried and fixed in ice-cold acetone for 10 minutes, then rehydrated with PBS for 5 minutes, blocked with protein block (DAKO) for 20 minutes, and incubated in mouse anti-human GM-CSF antibody diluted to 1:20 in PBS (R\&D Systems) for 1 hour at room temperature. Staining specificity was tested by substituting mouse monoclonal IgG isotype of the anti-human GM-CSF antibody (R\&D Systems) for the primary antibody. After three washes in PBS, sections were incubated with fluorescein isothiocyanate-conjugated goat anti-mouse antibody (1:100; Millipore; Temecula, CA) or rabbit anti-mouse antibody (1: 100; DAKO) for 1 hour. The sections were then washed three times and incubated in goat anti-human vimentin antibody (1:100; Sigma-Aldrich) or rabbit anti-human CD45 antibody (1:200; AbD Serotec, Raleigh, NC) for 1 hour at room temperature. After three washes in PBS, sections were incubated with rhodamineconjugated rabbit anti-goat antibody (1:400; Sigma-Aldrich) or goat anti-rabbit antibody (1: 100; Millipore; Temecula, CA) for 1 hour. Finally, the sections were washed quickly in PBS three times, stained with $4^{\prime}, 6^{\prime}$-diamidino2-phenylindole (DAPI) diluted 1: $5 \times 10^{5}$ in $\mathrm{dd}_{2} \mathrm{O}$ (Sigma-Aldrich), and mounted in a non-fade mounting medium (Life Sciences International, Basingstoke, UK). Immunofluorescence was examined under a Zeiss microscope (Müchen-Hallbergmoos, Germany) equipped with a cooled charge-coupled device camera (Axiocam $\mathrm{HRm}$, Zeiss). No cross-reaction was found between these antibodies.

\section{Cell Cultures}

Decidual specimens from elective terminations between 6 and 12 weeks of gestation were collected under Yale University Human Investigation Committee approval. The villous cytotrophoblasts were dissected from the decidua by forceps. Pulverized tissues was digested in $0.1 \% \mathrm{col}$ lagenase type IV and $0.01 \%$ DNase in RPMI 1640 containing $20 \mu \mathrm{g} / \mathrm{ml}$ penicillin/streptomycin, $1 \mu \mathrm{l} / \mathrm{ml}$ fungizone) (Invitrogen Inc., Grand Island, NY) in a $37^{\circ} \mathrm{C}$ shaking water bath for 30 minutes. After washing with sterile $1 \times$ PBS, the digestate was washed $\times 3$ and subjected to consecutive filtration through $100 \mu \mathrm{m}, 70 \mu \mathrm{m}$, and $40 \mu \mathrm{m}$ Millipore filters, respectively. Cells were resuspended in RPMI 1640 and then seeded on polystyrene tissue culture plates. The presence of leukocytes after each passage was monitored by flow cytometric analysis with anti-CD45 and anti-CD14 mAbs (BD Pharmingen, San Diego, CA). Cell cultures were found to be leukocyte-free $(<1 \%)$ after $3-4$ passages. Cultured decidual cells were found to be vimentin-positive and cy- tokeratin-negative and displayed decidualization-related morphological and biochemical changes during incubation with a progestin. The latter include enhanced expression of prolactin and plasminogen activator inhibitor-1 and inhibited expression of interstitial collagenase and stromelysin- 1 and as we recently demonstrated prolonged up-regulation of tissue factor mRNA and protein expression. ${ }^{20}$ Cell aliquots after harvest using trypsin/ EDTA were then frozen in fetal calf serum/DMSO $(9: 1)$ (Sigma-Aldrich) and stored in liquid nitrogen.

Thawed first trimester decidual cells $\left(5 \times 10^{5}\right.$ cells per $\mathrm{ml}$ ) were suspended in basal medium, a phenol red-free 1:1 (vol/vol) mix of DMEM (Invitrogen, Inc.) and Ham's F-12 (Flow Laboratories, Rockville, MD) containing 100 $\mathrm{U} / \mathrm{ml}$ penicillin, $100 \mu \mathrm{g} / \mathrm{ml}$ streptomycin, $0.25 \mu \mathrm{g} / \mathrm{ml}$ fungizone supplemented with $10 \%$ charcoal-stripped calf serum. The decidual cells were seeded onto polystyrene tissue culture flasks coated with 2\% type B gelatin (Sigma-Aldrich), grown to confluence in a standard $95 \%$ air:5\% CO2 incubator at $37^{\circ} \mathrm{C}$, and passaged $\times 6$ then grown to confluence. Confluent decidual cells were incubated for 7 days in basal medium + charcoal-stripped calf serum containing $10^{-8} \mathrm{~mol} / \mathrm{L}$ estradiol plus $10^{-7}$ $\mathrm{mol} / \mathrm{L}$ medroxyprogesterone acetate (Sigma-Aldrich) with one change of medium. The cultures were washed twice with HBSS to remove residual serum components and switched to a serum-free defined medium consisting of basal medium plus ITS + (BD Biosciences, Bedford, MA), $5 \mu \mathrm{m} \mathrm{FeSO} 4,50 \mu \mathrm{m}$ ZnSO4, $1 \mathrm{~nm}$ CuSO $4,20 \mathrm{~nm}$ $\mathrm{Na} 2 \mathrm{SeO} 3$, trace elements (Invitrogen, Inc.), $50 \mu \mathrm{g} / \mathrm{ml}$ ascorbic acid (Sigma-Aldrich), and $50 \mathrm{ng} / \mathrm{ml}$ epidermal growth factor (BD Biosciences, Bedford, MA). Subsequently, the cells were incubated with steroids with or without $1 \mathrm{ng} / \mathrm{ml} \mathrm{IL-}-1 \beta$ or TNF- $\alpha$ for 6 hours (total RNA purification) or 24 hours (protein extraction).

\section{Quantitative Reverse Transcription-Polymerase Chain Reaction (qRT-PCR)}

\section{Human Decidual Cells}

The primer pairs were synthesized and gel purified at the Yale DNA Synthesis Laboratory (Critical Technologies). Reverse transcription was initially carried out using Omniscript kit (Qiagen, Valencia, CA) in an Eppendorf Mastercycler Gradient (Eppendorf, Hamburg, Germany). Each RT reaction contained $2 \mu \mathrm{g}$ of total RNA, $2 \mu \mathrm{l} 1 \mathrm{x}$ buffer RT, 0.5 mmol/L dNTPs, $1 \mu \mathrm{mol} / \mathrm{L}$ T7-(dT)24 oligoprimer and 4 units of Omniscript reverse transcriptase. This $20-\mu$ l reaction was immediately incubated at $37^{\circ} \mathrm{C}$ for 1 hour. Specific primer sets were designed accordingly to each gene for quantitative PCR. The sequences of these primer sets are shown in Table 1. A quantitative standard curve was then created using a range of RT products. The curve was created with the Roche Light Cycler (Roche, Indianapolis, IN) by monitoring the increasing fluorescence of PCR products during amplification. Once the standard curve was established, quantification of unknowns was determined with the Roche Light Cycler and adjusted to the quantitative expression of $\beta$-actin from these same unknowns. Melting curve analysis was conducted to 
Table 1. Sequences of Primer Sets for First-Trimester Decidual Cell Cultures

\begin{tabular}{ccc}
\hline \multicolumn{1}{c}{ Gene } & Forward primers & \multicolumn{1}{c}{ Reverse primers } \\
\hline$\beta$-Actin & 5'-CGTACCACTGGCATCGTGAT-3' & 5' $^{\prime}$-GTGTTGGCGTACAGGTCTTTG-3' \\
GM-CSF & 5'-AACTTCCTGTGCAACCCAGATTAT-3' & 5'-ATGCCTGTATCAGGGTCAGTGT-3' $^{\prime}$ \\
\hline
\end{tabular}

determine the specificity of the amplified products and the absence of primer-dimer formation.

\section{Murine Samples}

Total RNA $(2 \mu \mathrm{g})$ was transcribed to cDNA using dNTPs (2.5 mmol/L, Amersham, Freiburg, Germany), RB (Moloney mouse leukemia virus), RT-buffer, DNase (2 $\mathrm{U} / \mu \mathrm{l}$, Stratagene, Amstelveen, Netherland), and RNase inhibitor (40 $\mathrm{U} / \mu \mathrm{l}$, Promega, Mannheim, Germany) at $37^{\circ} \mathrm{C}$ for 30 minutes, then heated at $75^{\circ} \mathrm{C}$ for 5 minutes. Reverse transcriptase $(200 \mathrm{U} / \mu \mathrm{l})$ and RNase inhibitor were added and incubated at $42^{\circ} \mathrm{C}$ for 1 hour, then $95^{\circ} \mathrm{C}$ for 5 minutes and cooling on ice. Reactions were carried out with $1 \mu \mathrm{l} \mathrm{cDNA}$, $6.5 \mu \mathrm{l}$ Sybr-Green-Mastermix (Stratagene), $2 \mu \mathrm{l}$ RNase-free water, $3 \mu \mathrm{l}$ primers, and $0.5 \mu \mathrm{l}$ Fluorescein (25 nmol/L, Fermentas, St. Leon-Rot, Germany) with results normalized to $\beta$-actin. The sequences of these primer sets are shown in Table 2.

\section{ELISA}

\section{Placental Bed Biopsies}

Frozen decidual tissues were homogenized in RIPA lysis buffer (NP-40 2\%, SDS 0.02\%, sodium deoxycholate $1 \%$, $1 \times \mathrm{PBS})$ with protease inhibitor cocktail (Sigma-Aldrich). Total protein $(25 \mu \mathrm{g} / \mathrm{ml})$ was used to detect the GM-CSF levels by ELISA kit as manufacturer's protocol (R\&D Systems). The GM-CSF levels are expressed as $\mathrm{pg} / \mathrm{ml}$.

\section{First Trimester Decidual Cell Cultures}

Whole cell lysates prepared from cultured decidual cells were used to measure total cell protein levels by the Bio-Rad Assay (Bio-Rad Laboratories, Inc. Hercules, CA). A commercial ELISA kit measured immuno-reactive levels of GM-CSF in conditioned media according to instructions provided by the manufacturer (R\&D Systems). The ELISA has a sensitivity of $<10 \mathrm{pg} / \mathrm{ml}$. The intra-assay and interassay coefficients of variation vary from 2.3 to 2.6 and from 5.0 to 6.5 , respectively.

\section{Cell Differentiation Assay}

Peripheral blood was collected from adult nonpregnant healthy reproductive age female donors. The CD14+ monocytes isolated from buffy coats $^{26}$ using CD14 MicroBeads (Miltenyi Biotec, Auburn, CA) were incubated with conditioned media from TNF- $\alpha$ or IL- $1 \beta$-treated or -untreated first trimester decidual cells with or without anti-GMCSF neutralizing antibody (R\&D Systems) for 5 days. For dendritic cell differentiation, $20 \mathrm{ng} / \mathrm{ml}$ of human recombinant IL-4 (R\&D Systems) was added. The identity of macrophages and dendritic cells was confirmed by flow cytometry using anti-CD68-PE and anti-CD11c-fluorescein isothiocyanate antibodies (R\&D Systems), respectively.

\section{Statistical Analysis}

The Kolmogorov-Smirnov one-sample test was used to distinguish normally from nonnormally distributed results to apply the appropriate parametric or nonparametric tests. Tissue and cell ELISAs, immunohistochemistry, qRT-PCR as well as cell differentiation assay results are presented as mean \pm SEM. All parameters are expressed as mean \pm SEM. The differences were assessed by Wilcoxon Signed Ranks test or the Student's t-test, when appropriate. A $P$ value less than 0.05 was considered significant.

\section{Results}

\section{GM-CSF Expression Is Increased in Decidua from Preeclamptic Women}

For immunostaining of formalin-fixed paraffin-embedded serial sections, GM-CSF was significantly greater in the cytoplasm of decidual cells from preeclamptic (Figure 1B) compared with control specimens (Figure 1A). Decidual cells are identified by the positive vimentin staining in control (Figure 1C) and preeclamptic specimens (Figure 1D). Co-immunostaining of the panleukocyte maker, CD45 (Figure 1, E and F), or vimentin (Figure 1, G and H), and GM-CSF in serial frozen sections showed that changes in GM-CSF expression were found primarily in decidual cells, which are large vimentin-positive CD45-negative cells. These observations were confirmed by demonstrating greater prominence of yellow immunofluorescence denoting colocalization of GM-CSF (green) and vimentin (red) in a preeclamptic (Figure $1 \mathrm{H}$ ) versus gestational agematched control specimen (Figure 1G). Table 3 sum-

Table 2. Sequences of Primer Sets for Mouse Placenta

\begin{tabular}{|c|c|c|}
\hline Gene & Forward primers & Reverse primers \\
\hline $\begin{array}{l}\beta \text {-Actin } \\
\text { GM-CSF }\end{array}$ & $\begin{array}{l}\text { 5'-GCTTCTTTGCAGCTCCTTCGTT-3' } \\
5^{\prime}-\text { TGCGTAATGAGCCAGGAACT-3' }\end{array}$ & $\begin{array}{l}\text { 5'-GTTGTCGACGACCAGCGC-3' } \\
5^{\prime}-\text { TCTCGTTTGTCTTCCGCTTGT-3' }\end{array}$ \\
\hline
\end{tabular}




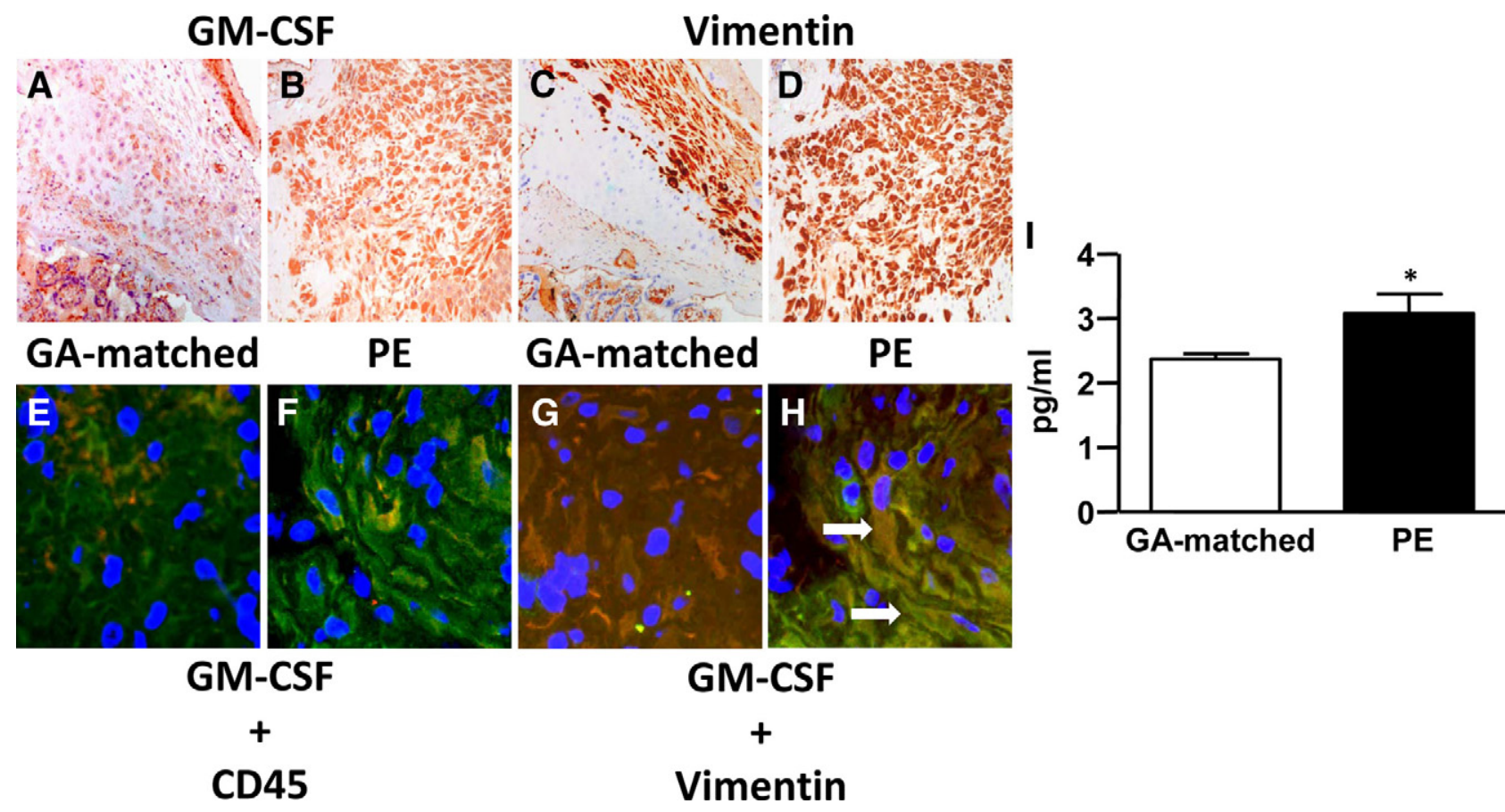

Figure 1. Expression of GM-CSF is increased in decidual cells from preeclamptic women. Representative serial sections for GM-CSF immunostaining of $(\mathbf{A}, \times 200$ ) gestational age (GA)-matched control and $(\mathbf{B}, \times 200)$ preeclamptic paraffin-embedded decidual tissues visualized by DAB staining. $(\mathbf{C}$ and $\mathbf{D}$, $\times 200)$ Serial sections from corresponding tissue were stained for the decidual cell marker, vimentin. The expression of GM-CSF in decidua was also assessed by colocalization of immunofluorescence staining of frozen sections. Yellow staining indicates colocalization of individual staining of GM-CSF (green) and (E and $\mathbf{F}, \times 400) \mathrm{CD} 45$ (red) or $(\mathbf{G}$ and $\mathbf{H}, \times 400)$ vimentin (red). The arrows indicate the large GM-CSF and vimentin double-positive cells. I: ELISA of GM-CSF expression in extracts of decidual tissues from GA-matched and preeclamptic patients $\left(n=8,{ }^{*} P<0.05\right)$.

marizes the immunostaining results for the formalinfixed paraffin-embedded sections. It indicates that compared with control decidual sections, decidua from preeclamptic women more frequently displayed prominent immunostaining. Consistent with the results of immunostaining, extracts of decidual tissues from preeclamptic patients contain significantly elevated levels of immuno-reactive GM-CSF (Figure 1I) $(P<0.05)$.

\section{GM-CSF Expression Is Induced by IL-1 $\beta$ and TNF- $\alpha$ in Cultured First Trimester Decidual Cells}

Figure 2A uses a log scale and indicates that TNF- $\alpha$ and IL-1 $\beta$ up-regulated steady state GM-CSF mRNA expression in estradiol and medroxyprogesterone acetate primed leukocyte-free first trimester decidual cells by 20-fold $(n=3, P<0.05)$ and 180-fold $(n=5, P<0.005)$ (Figure 2A), respectively. In parallel incubations, corresponding effects were observed on secreted levels of GM-CSF measured by a specific ELISA (Figure 2B). Spe-

Table 3. Immunohistochemical Analysis of Decidual GM-CSF Expression in Preeclampsia and Control Specimens

\begin{tabular}{lccc}
\hline & \multicolumn{3}{c}{ GM-CSF immunostaining } \\
\cline { 2 - 4 } & ++ & + & $0 /+$ \\
\hline Preeclampsia & 5 & 3 & 0 \\
Controls & 0 & 5 & 3 \\
\hline
\end{tabular}

The following scoring system was used: ++ , marked staining; + , moderate staining; and $0 /+$, weak staining. cifically, GM-CSF expression was found to be significantly up-regulated by TNF- $\alpha$ and IL- $1 \beta$ by threefold ( $n=$ 6, $P<0.05)$ and 123-fold $(n=6, P<0.005)$ respectively.

\section{Inflammatory Cytokine-Enhanced GM-CSF Expression by First Trimester Decidual Cells Mediates Differentiation of Monocytes to Macrophages and Dendritic Cells}

To elucidate potential mechanism(s) by which augmented GM-CSF expression by decidual cells may mediate the characteristic excess of macrophages and dendritic cells found in decidua from preeclamptic women,, 6
A

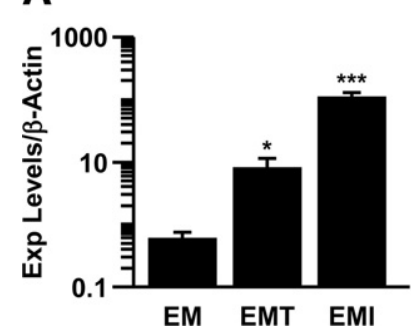

B

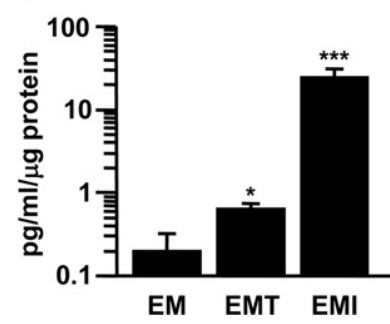

Figure 2. TNF- $\alpha$ and IL-1 $\beta$ induce GM-CSF expression in leukocyte-free first-trimester decidual cells. A: qRT-PCR of GM-CSF in first-trimester decidual cells treated with or without TNF- $\alpha$ (EMT) or IL-1 $\beta$ (EMI). The results were normalized to $\beta$-actin. B: ELISA of GM-CSF in the conditioned media of first-trimester decidual cells treated with or without TNF- $\alpha$ or IL- $1 \beta$; the results were normalized to total cell protein $\left(n=3-6,{ }^{*} P<0.05,{ }^{* * *} P<\right.$ $0.005)$. The plots are shown in log scale. 
A

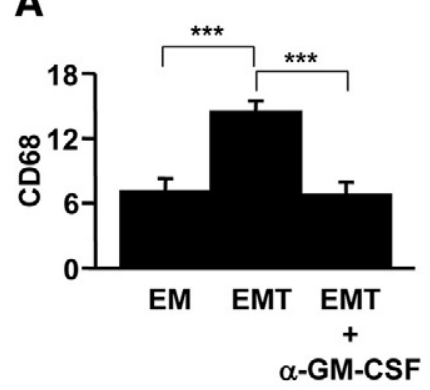

E
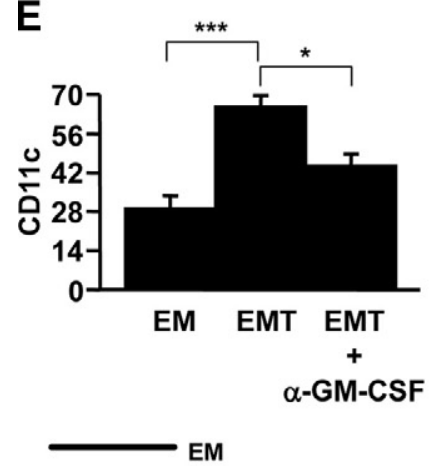

- - - - EMT

EMT + $\alpha-G M-C S F$
B

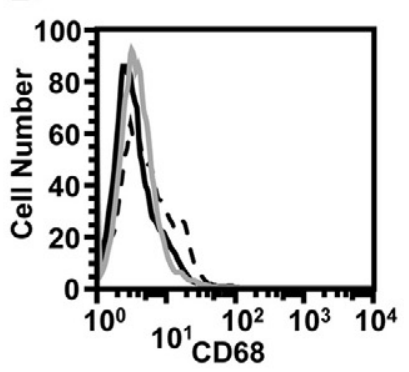

$\mathbf{F}$

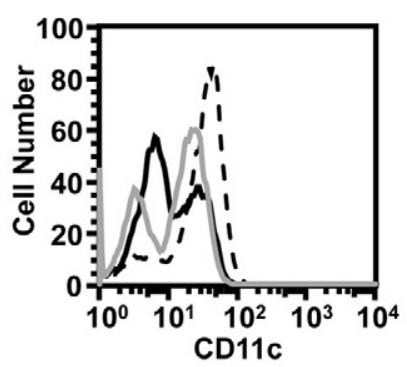

C

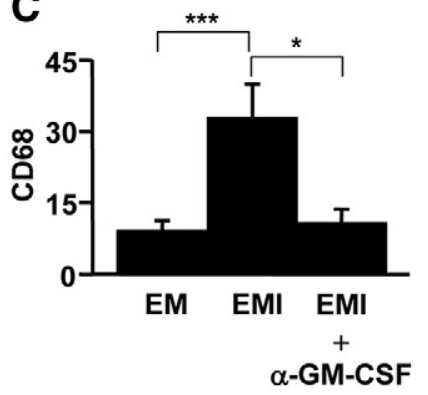

G

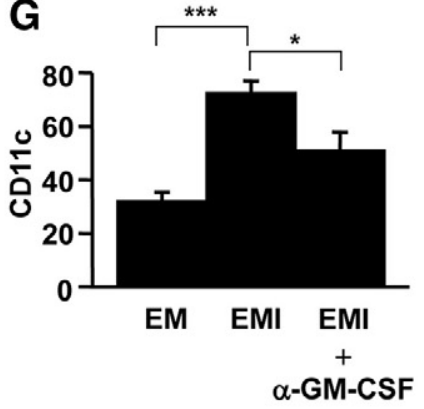

D

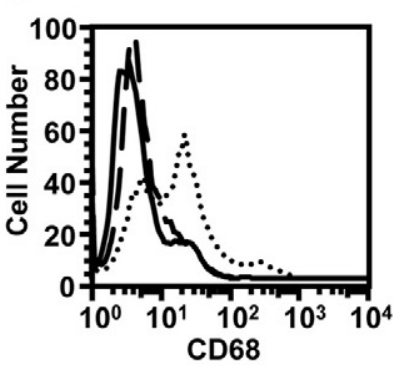

H

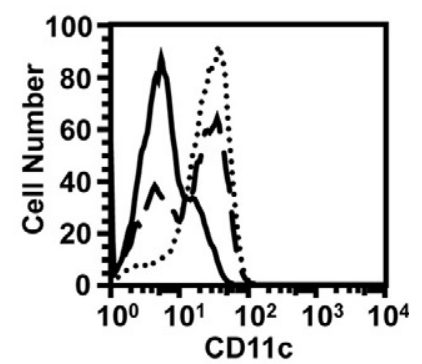

EM

…...... EMI

$-\mathrm{EMI}+\alpha-\mathrm{GM}-\mathrm{CSF}$

Figure 3. The development of macrophages and dendritic cells was enhanced by TNF- $\alpha$ - or IL-1 $\beta$-treated first-trimester decidual cell-derived GM-CSF. Monocytes isolated from peripheral blood were incubated with conditioned media from leukocyte-free first-trimester decidual cells treated with estradiol + medroxyprogesterone acetate \pm TNF- $\alpha$ (EMT) or IL-1 $\beta$ (EMI) in the presence or absence of anti-human GM-CSF-neutralizing antibody ( $\alpha$-GM-CSF). Expression of (A-D) the macrophage (CD68) or ( $\mathbf{E}-\mathbf{H})$ dendritic cell (CD11c) surface marker was examined by flow cytometric analysis $\left(n=5-9,{ }^{*} P<0.05,{ }^{*} * * * 20.005\right)$. Histograms of flow cytometric analysis for surface marker expression are from representative experiments. Black line: EM; Short dash line: EMT; Gray line: EMT + $\alpha$-GM-CSF; Dot line: EMI; Long dash line: EMI $+\alpha$-GM-CSF.

the functional role of enhanced GM-CSF expression in first trimester decidual cells was evaluated on the differentiation of monocytes to macrophages or dendritic cells. Conditioned medium from TNF- $\alpha$ - or IL- $1 \beta$-treated first trimester decidual cells enhanced the differentiation of monocytes isolated from peripheral blood to either macrophages (CD68) (Figure 3, A-D; $n=5-7, P<0.005$ ) or dendritic cells (CD11C) (Figure 3, E-H; $n=5-9, P<$ $0.005)$ by $51-73 \%$. Exposure to GM-CSF neutralizing antibody inhibited TNF- $\alpha$ - or IL-1 $\beta$-treated first trimester decidual cell-induced monocyte differentiation to macrophages or dendritic cells by 51-66\% (Figure 3, A-D; $n=$ 5-7, $P<0.005$ for macrophages and $P<0.05$ for dendritic cells) and 30-32\% (Figure 3, E-H; $n=5-9, P<$ $0.05)$, respectively. These results are consistent with a key role played by decidual cell-derived GM-CSF in the pathogenesis of preeclampsia in view of the marked excess of macrophages and dendritic cells in decidua from preeclamptic women.

\section{Murine Preeclampsia Is Associated with Increased Decidual GM-CSF Expression as Well as the Infiltration of Macrophages and Dendritic Cells}

Consistent with the maternal syndrome of preeclampsia in humans, transfer of activated Th1-like splenocytes to recipient mice elicited an immediate increase in the systolic blood pressure of recipient mice measured on gestational day 14 (124 $\pm 8 \mathrm{mmHg}$ for PBS treated controls versus $146 \pm 20 \mathrm{~mm} \mathrm{Hg}$ for preeclamptic mice, $P<$ $0.001)$ and induced proteinuria $(>1 \mathrm{~g} / \mathrm{L})$ in preeclamptic mice (Supplemental Figure 1B at http://ajp.amjpathol.org). Hematoxylin and eosin staining demonstrated extensive edema, hemorrhage, and tissue damage in the decidual and spongiotrophoblast layer of utero-placental units from pregnant activated Th1-like cell recipients (preeclamptic mice) (Figure 4, B and D) compared to controls (Figure 4, A and $\mathrm{C}$ ). As expected, staining of kidney sections revealed glomeruli without histopathological change in control pregnant mice (Figure 4E); however, renal hemorrhage and abnormal glomerular cell infiltration were observed in pregnant cell recipients (Figure 4F).

Further links between elevated GM-CSF expression in the placenta and the onset of preeclamptic symptoms were established by demonstrating that, compared with control mice, recipients of activated Th1-like splenocytes displayed augmented levels of GM-CSF mRNA (Figure $5 A$ ) and increased expression of immuno-reactive GMCSF (Figure 5, B, C, and H). Consistent with an increase of macrophages and dendritic cells in the human decidua from preeclamptic women, the numbers of macrophages (Figure 5, D, E, and I) and dendritic cells (Figure $5, F, G$, and J) were also increased in the decidua of activated Th1-like cell recipient mice. 
PBS
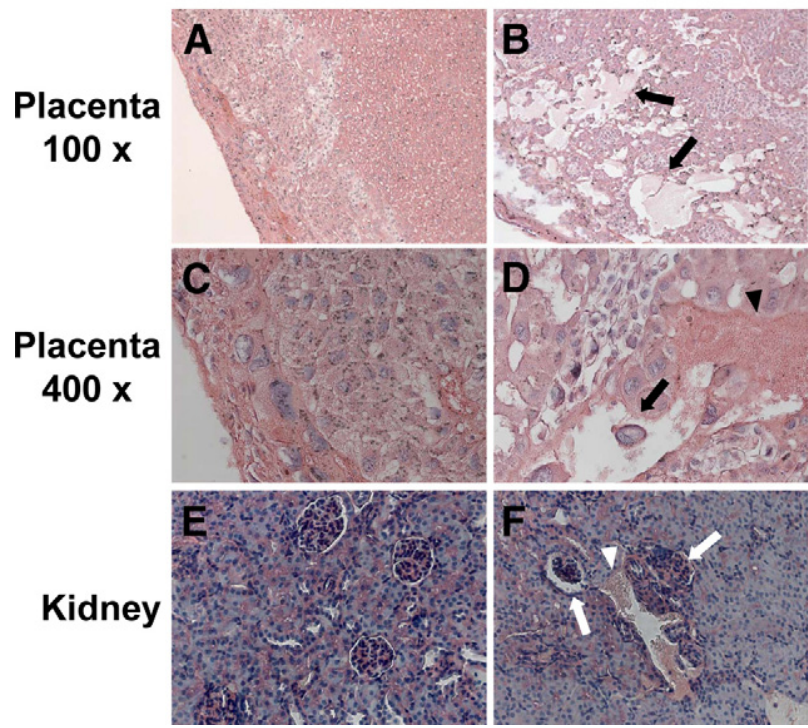

Figure 4. Histopathological changes in the utero-placental units and kidneys in preeclamptic mice. Eight-week-old female BALB/c mice mated with male $\mathrm{C} 57 \mathrm{BL} / 6$ mice were injected with either PBS or $3 \times 10^{7}$ activated Th1-like splenocytes isolated from spleen on gestational days 10 and 12 . Samples were collected at gestational day 14. The paraffin-embedded uteroplacental units and kidneys were stained with hematoxylin and eosin. A $(\times 100)$ and $\mathbf{C}(\times 400)$ : The tissue was intact in placenta from PBS-injected mice. B $(\times 100)$ and $\mathbf{D}(\times 400)$ : Extensive edema (black arrows) and hemorrhage (black arrowhead) were found in the spongiotrophoblast layer of placenta from activated Th1-like cell recipient. E $(\times 200)$ : No histopathological change was found in the kidney from PBS-injected mice. F $(\times 200)$ : Hemorrhage (white arrowhead) and increase of cell infiltration (white arrows) in glomeruli were shown in the kidney from an activated Th1-like cell recipient.

\section{Discussion}

In the United States, preeclampsia complicates 5 to $10 \%$ of pregnancies and accounts for 12 to $18 \%$ of all pregnancy-related maternal death. ${ }^{3,27}$ It is also a major cause of intrauterine growth restriction (10-25\% of women with preeclampsia) and prematurity and is associated with various long-term neonatal morbidities. ${ }^{28,29}$ Delivery of the placenta remits the immediate clinical manifestations of preeclampsia and remains the only reliable treatment for preeclampsia. However, longitudinal studies indicate that the occurrence of preeclampsia whether treated or not, carries severe long-term maternal health risks such as accelerated cardiovascular death. ${ }^{30}$

While the placental pathogenesis of most cases of preeclampsia appears to be initiated in early pregnancy ( $<18-20$ weeks) as a consequence of shallow extravillous cytotrophoblast invasion of the decidua, ${ }^{31}$ the signs and symptoms of preeclampsia are generally evident much later, usually in the third trimester. The onset of clinical manifestations reflects endothelial cell activation, vasospasm, glomerular and hepatocyte damage, and central nervous syndrome changes. This temporal disconnection between placental pathology and maternal systemic manifestations has posed a major obstacle in attempts to elucidate the real-time placental pathogenesis of this disorder or developing earlier diagnoses or preventative therapies. Our laboratory has used a twotiered approach in attempting to overcome this obstacle.
Initial observations revealed that in situ observations determine that numbers of macrophages as well as immature and mature dendritic cells are significantly increased in decidual cells of preeclamptic compared with gestational age-matched decidual sections. In correspondence with these increases in the two immune cell populations an array of monocyte/macrophage- and dendritic cell-recruiting chemokines were observed to be significantly elevated in decidua from preeclamptic women extracts as measured by ELISA and specifically in decidual cells by immunohistochemical localization.8,32 Subsequently, the second tier of our approach sought to determine by in vitro studies whether expression of these proteins is altered during incubation of first trimester leukocyte-free first trimester decidual cells with preeclampsia-associated proinflammatory cytokines, TNF- $\alpha$ and IL-1 $\beta$. These studies confirmed that TNF- $\alpha$ and IL-1 $\beta$ each markedly increased expression of monocyte/macrophage- and dendritic cell-recruiting chemokines in first trimester decidual cells, the major resident cell type encountered by invading extravillous cytotrophoblasts. Previous studies from our laboratory reported parallel observations for IL-6 expression (ie, enhanced IL-6 levels were immunolocalized to decidual cells of preeclamptic versus control placental sections with inflammatory cytokines augmenting IL-6 mRNA and protein expression in cultured leukocyte-free first trimester decidual cells). ${ }^{32,33}$ In several tissues, IL-6 mediates the transition from acute to chronic inflammation by reciprocally inhibiting neutrophil trafficking and promoting monocyte differentiation away from dendritic cells toward macrophages. ${ }^{33}$ Taken together, previous reports from our laboratory indicate a crucial role for decidual cells in determining the macrophage and dendritic cell population of the decidua from preeclamptic women.

The pivotal role played by GM-CSF in modulating differentiation of monocytes to macrophages and/or dendritic cells stimulated the current study to search for an association between decidual cell GM-CSF expression and preeclampsia-related trafficking of both immune cell types. Previously, decidual GM-CSF was shown to originate from T-lymphocytes responding to alloantigens, ${ }^{34}$ whereas GM-CSF expression was not assessed in decidua from preeclamptic women. Seeking to fill in this gap in our knowledge, the current study found that: i) immuno-reactive GM-CSF levels are elevated in decidual cells of placental sections of patients with preeclampsia versus gestational-age matched controls; ii) GM-CSF mRNA and protein levels are enhanced in first trimester decidual cells during incubation with the preeclampsiarelated inflammatory cytokines, TNF- $\alpha$ and IL- $1 \beta$. These observations, taken together with the well-documented roles of macrophages and dendritic cells in preeclampsia-related events as detailed above as well as those of GM-CSF in activating both macrophages and dendritic cells, strongly suggest that decidual cell-derived GMCSF plays a regulatory role in the early pathogenesis of preeclampsia. Studies from our ${ }^{6}$ and other laboratories ${ }^{35}$ observed an increase in macrophages in the decidua of women with preeclampsia. In vitro observations indicate that macrophage-derived TNF- $\alpha$ inhibits extravillous cy- 


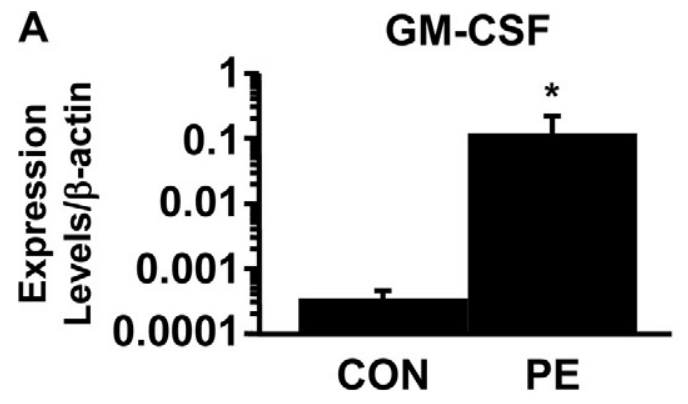

GM-CSF
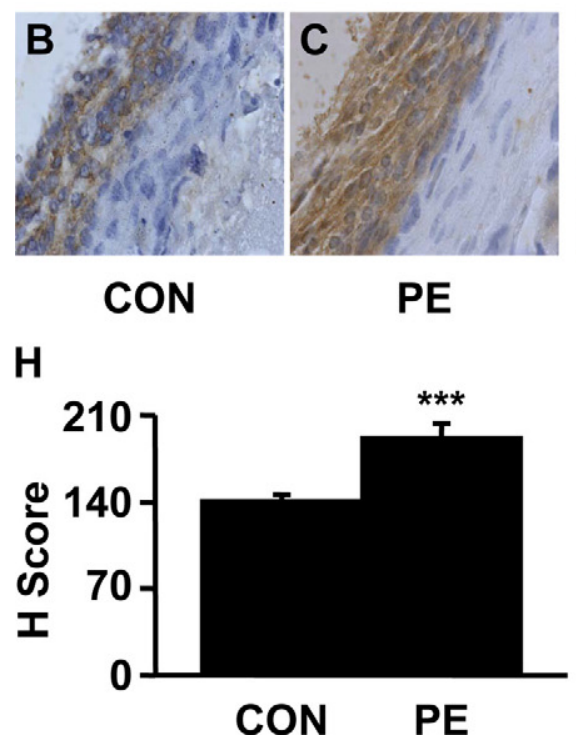

CON

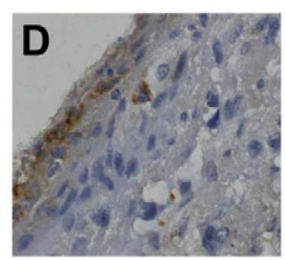

CON

I

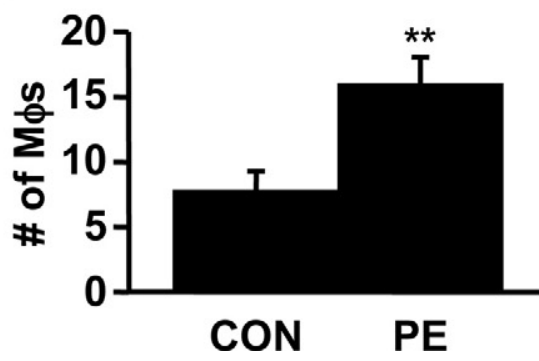

$\mathbf{M} \phi \mathbf{s}$

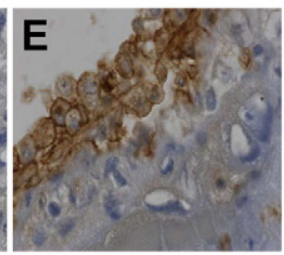

PE
Figure 5. The numbers of macrophages and dendritic cells as well as the expression of GM-CSF were increased in the decidua from preeclamptic mice. A: GM-CSF mRNA expression in placenta by qRT-PCR. The plot is shown in log scale. Th1-like cell transfer induced GM-CSF expression in the preeclamptic decidua. GM-CSF expression in the placenta from control $(\mathrm{CON} ; \mathbf{B})$ and preeclamptic $(\mathrm{PE} ; \mathbf{C})$ mice, macrophages $(\mathrm{M} \phi \mathrm{s})$ in the placenta from control (D) and preeclamptic (E) mice. Dendritic cells (DCs) in the placenta from control (F) and preeclamptic $(\mathbf{G})$ mice. Magnification, $\times 400$. H: H-score comparison of GM-CSF staining between control and preeclamptic decidua $\left(n=7,{ }^{*} * * *\right.$ 0.005). I: Comparison of the number of macrophages between control and preeclamptic decidua $\left(n=7,{ }^{* *} P<0.01\right)$. $\mathbf{J}$ : Comparison of the number of dendritic cells between control and preeclamptic decidua $\left(n=7,{ }^{*} P<0.05\right)$. Five different fields per sample were evaluated.
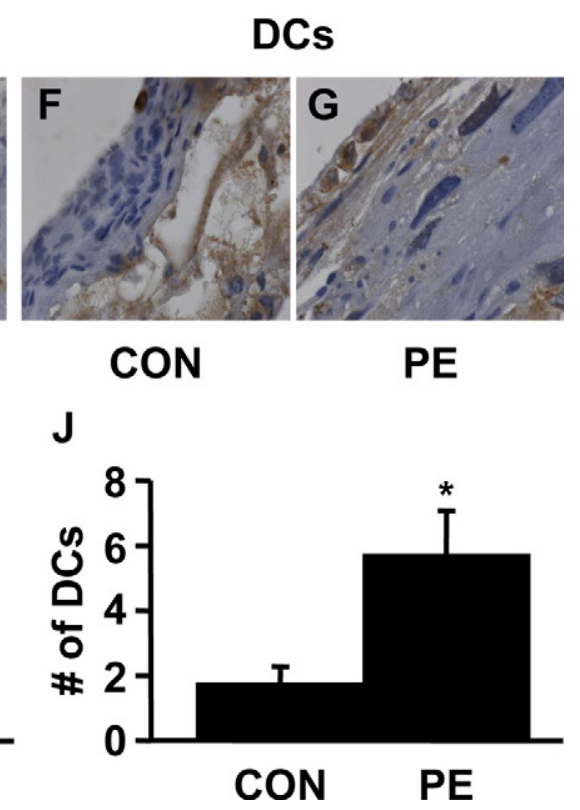

totrophoblast invasion by inducing apoptosis in extravillous trophoblasts, thereby interfering with extravillous cytotrophoblast-mediated decidual vascular remodeling to produce the characteristic placental hypoxia and maternal symptoms of preeclampsia. This effect was blocked by an antibody against the TNF- $\alpha$ receptor, ${ }^{35}$ whereas inhibition of extravillous cytotrophoblast invasiveness by lipopolysaccharide-activated macrophages was reversed by a TNF- $\alpha$ neutralizing antibody. ${ }^{36}$ Mediating this process by decidual cells was indicated by our observations that macrophages incubated with conditioned medium from IL- $1 \beta$-treated first trimester human decidual cells inhibited extravillous cytotrophoblast invasion. A report from our laboratory was the first to demonstrate a preeclampsia-related increase in decidual dendritic cells. ${ }^{8}$ However, dendritic cells incubated with conditioned medium from IL- $1 \beta$-treated first trimester human decidual cells did not impede extravillous cytotrophoblast invasion. Ongoing work in our laboratory suggests that the preeclampsia-related infiltration of dendritic cells into the decidua may induce a compensatory immune tolerance consistent with the reduced incidence and severity of preeclampsia in subsequent pregnancies. In vitro experiments are needed to determine whether co-incubation with either macrophages or dendritic cells in fact induces apoptotic changes in extravillous cytotrophoblasts.
While use of the two-tiered approach to include GMCSF in the current study has provided important insights into the pathogenesis of preeclampsia, we sought to extend this to a third tier by evaluating decidual expression of GM-CSF in a mouse model of preeclampsia. In particular, studies from the laboratory of Croy and associates have revealed similarities in implantation and placentation as well as the uterine immune cell population between the mouse and human. ${ }^{37} \mathrm{~A}$ growing body of evidence shows that mouse models provide important clues that have aided investigators in identifying proteins that are required to coordinate embryo and maternal interactions during the peri-implantation period. The use of this specific mouse model allowed us to investigate whether dendritic cell and GM-CSF expressed in dendritic cell may be related to the preeclampsia-like symptoms observed exclusively in pregnant mice 25,26 after transfer of activated Th1 cells. Such information has clear implications in elucidating the pathogenesis of preeclampsia. ${ }^{38,39}$ Specifically, the current study found that mice induced to exhibit preeclamptic symptoms (ie, proteinuria and hypertension) displayed elevated decidual GM-CSF expression together with significant macrophage and dendritic cell infiltration of the decidua.

Although several reports indicate that circulating IL-1 $\beta$ and TNF- $\alpha$ levels are elevated in women with preeclampsia, the source of these increases is unclear. However, 
these changes appear to represent exaggeration of the normal peri-implantational decidual macrophage infiltration. Compared with levels of IL-1 $\beta$, the follicular and peri-ovulatory phase human endometrium contains a 10to 30 -fold excess of IL-1 receptor antagonist (IL-1Ra), which blocks the IL-1 receptor. A decline in glandular IL-1Ra levels coincides with the "window of implantation." ${ }^{\prime 0}$ Observations in our laboratory suggest that the resulting free IL-1 $\beta$ enhances expression of several monocyte recruiting and activating chemokines in decidual cells that promote a physiological monocyte influx during early gestation but is normally transient because extravillous cytotrophoblasts release IL-1Ra. ${ }^{41,42}$ However, increased expression of IL-1 $\beta$ in significant subsets of preeclampsia cases accompanying maternal infections, such as Chlamydia ${ }^{43,44}$ and viruses, ${ }^{45,46}$ and other inflammatory states may overwhelm this block of the IL-1R by IL-1Ra. In addition, TNF- $\alpha$ and IL-1 $\beta$ polymorphisms are associated with impaired extravillous cytotrophoblast invasion, preeclampsia, and eclampsia. ${ }^{47-51}$ Elevated levels of TNF- $\alpha$ or IL- $1 \beta$ associated with inflammatory states or maternal genetic polymorphisms target decidual cells to enhance synthesis and secretion of monocyte/macrophage- and dendritic cell-recruiting chemokines and CSFs to enhance recruitment/differentiation/activation of macrophages and dendritic cells. Because macrophages are a rich source of TNF- $\alpha$, the concerted actions of IL-1 $\beta$ and macrophage-derived TNF- $\alpha$ may promote a feed-forward cycle to promote an excess of decidual macrophages in preeclampsia. The resulting impaired extravillous cytotrophoblast invasion and incomplete remodeling of the spiral arteries which decreases utero-placental blood flow to produce placental hypoxia. That hypoxia-reoxygenation enhances output of TNF- $\alpha$ in human placental tissue ${ }^{52}$ suggests that the placenta is an additional source of TNF- $\alpha$.

In summary, the current use of a three-tier approach (ie, in situ and in vivo measurements in human decidual cells followed by in vivo confirmation) in the decidua of a mouse model for preeclampsia suggests that elevated GM-CSF expression plays an integral role in the pathogenesis of preeclampsia. Future studies that use GMCSF null mice and extend the strategy used in the current study to include other preeclampsia-associated proteins offer great promise in making strides in the diagnosis and treatment of this major pathology of human pregnancy.

\section{References}

1. Duley L: Maternal mortality associated with hypertensive disorders of pregnancy in Africa, Asia, Latin America and the Caribbean. Br J Obstet Gynaecol 1992, 99:547-553

2. Caniggia I, Winter J, Lye SJ, Post M: Oxygen and placental development during the first trimester: implications for the pathophysiology of pre-eclampsia. Placenta 2000, 21 (Suppl A):S25-S30

3. Sibai B, Dekker G, Kupferminc M: Pre-eclampsia. Lancet 2005, 365:785-799

4. Piccinni MP: Role of immune cells in pregnancy. Autoimmunity 2003, 36:1-4

5. Dekker GA, Sibai BM: The immunology of preeclampsia. Semin Perinatol 1999, 23:24-33

6. Lockwood CJ, Matta P, Krikun G, Koopman LA, Masch R, Toti P,
Arcuri F, Huang SJ, Funai EF, Schatz F: Regulation of monocyte chemoattractant protein-1 expression by tumor necrosis factor- $\alpha$ and interleukin- $1 \beta$ in first trimester human decidual cells: implications for preeclampsia. Am J Pathol 2006, 168:445-452

7. Reister F, Frank HG, Heyl W, Kosanke G, Huppertz B, Schroder W Kaufmann $P$, Rath $\mathrm{W}$ : The distribution of macrophages in spiral arteries of the placental bed in pre-eclampsia differs from that in healthy patients. Placenta 1999, 20:229-233

8. Huang S, Chen CP, Schatz F, Rahman M, Abrahams V, Lockwood C Pre-eclampsia is associated with dendritic cell recruitment into the uterine decidua. J Pathol 2008, 214:328-336

9. Abrahams VM, Kim YM, Straszewski SL, Romero R, Mor G: Macrophages and apoptotic cell clearance during pregnancy. Am J Reprod Immunol 2004, 51:275-282

10. Barreda DR, Hanington PC, Belosevic M: Regulation of myeloid development and function by colony stimulating factors. Dev Comp Immunol 2004, 28:509-554

11. Takahashi K, Naito M, Takeya M: Development and heterogeneity of macrophages and their related cells through their differentiation pathways. Pathol Int 1996, 46:473-485

12. Nauta AJ, Kruisselbrink AB, Lurvink E, Willemze R, Fibbe WE: Mesenchymal stem cells inhibit generation and function of both CD34+derived and monocyte-derived dendritic cells. J Immunol 2006, 177:2080-2087

13. Robertson SA, Mayrhofer G, Seamark RF: Uterine epithelial cells synthesize granulocyte-macrophage colony-stimulating factor and interleukin-6 in pregnant and nonpregnant mice. Biol Reprod 1992, 46:1069-1079

14. Sharpe-Timms KL, Bruno PL, Penney LL, Bickel JT: Immunohistochemical localization of granulocyte-macrophage colony-stimulating factor in matched endometriosis and endometrial tissues. Am J Obstet Gynecol 1994, 171:740-745

15. Giacomini G, Tabibzadeh SS, Satyaswaroop PG, Bonsi L, Vitale L, Bagnara GP, Strippoli P, Jasonni VM: Epithelial cells are the major source of biologically active granulocyte macrophage colony-stimulating factor in human endometrium. Hum Reprod 1995, 10:32593263

16. Zhao $\mathrm{Y}$, Chegini $\mathrm{N}$ : The expression of granulocyte macrophagecolony stimulating factor (GM-CSF) and receptors in human endometrium. Am J Reprod Immunol 1999, 42:303-311

17. Uzumaki H, Okabe T, Sasaki N, Hagiwara K, Takaku F, Tobita M, Yasukawa K, Ito S, Umezawa Y: Identification and characterization of receptors for granulocyte colony-stimulating factor on human placenta and trophoblastic cells. Proc Natl Acad Sci USA 1989, 86:9323-9326

18. Hayashi M, Hamada $Y$, Ohkura T: Elevation of granulocyte-macrophage colony-stimulating factor in the placenta and blood in preeclampsia. Am J Obstet Gynecol 2004, 190:456-461

19. Gratacos E, Filella X, Palacio M, Cararach V, Alonso PL, Fortuny A: Interleukin-4, interleukin-10, and granulocyte-macrophage colony stimulating factor in second-trimester serum from women with preeclampsia. Obstet Gynecol 1998, 92:849-853

20. Lockwood CJ, Murk W, Kayisli UA, Buchwalder LF, Huang ST, Funai EF, Krikun G, Schatz F: Progestin and thrombin regulate tissue factor expression in human term decidual cells. J Clin Endocrinol Metab 2009, 94:2164-2170

21. National high blood pressure education program working group on high blood pressure in pregnancy: Report of the National High Blood Pressure Education Program Working Group on High Blood Pressure in Pregnancy. Am J Obstet Gynecol 2000, 183:S1-S22

22. Zenclussen AC, Fest S, Joachim R, Klapp BF, Arck PC: Introducing a mouse model for pre-eclampsia: adoptive transfer of activated Th1 cells leads to pre-eclampsia-like symptoms exclusively in pregnant mice. Eur J Immunol 2004, 34:377-387

23. Schmid M, Sollwedel A, Thuere C, Wafula PO, Zenclussen ML, Muller DN, Gratze P, Woiciechowsky C, Volk HD, Zenclussen AC: Murine pre-eclampsia induced by unspecific activation of the immune system correlates with alterations in the eNOS and AT1 receptor expression in the kidneys and placenta. Placenta 2007, 28:688-700

24. Kayisli UA, Selam B, Demir R, Arici A: Expression of vasodilatorstimulated phosphoprotein in human placenta: possible implications in trophoblast invasion. Mol Hum Reprod 2002, 8:88-94

25. Guzeloglu Kayisli O, Kayisli UA, Luleci G, Arici A: In vivo and in vitro 
regulation of Akt activation in human endometrial cells is estrogen dependent. Biol Reprod 2004, 71:714-721

26. Abrahams VM, Cambridge G, Lydyard PM, Edwards JC: Induction of tumor necrosis factor alpha production by adhered human monocytes: a key role for Fcgamma receptor type IIla in rheumatoid arthritis. Arthritis Rheum 2000, 43:608-616

27. Norwitz ER, Funai EF: Expectant management of severe preeclampsia remote from term: hope for the best, but expect the worst. Am J Obstet Gynecol 2008, 199:209-212

28. Hack M, Taylor HG, Klein N, Eiben R, Schatschneider C, MercuriMinich N: School-age outcomes in children with birth weights under 750 g. N Engl J Med 1994, 331:753-759

29. Halsey CL, Collin MF, Anderson CL: Extremely low birth weight children and their peers: a comparison of preschool performance. Pediatrics 1993, 91:807-811

30. Funai EF, Friedlander Y, Paltiel O, Tiram E, Xue X, Deutsch L, Harlap S: Long-term mortality after preeclampsia. Epidemiology 2005, 16: 206-215

31. Kaufmann P, Black S, Huppertz B: Endovascular trophoblast invasion: implications for the pathogenesis of intrauterine growth retardation and preeclampsia. Biol Reprod 2003, 69:1-7

32. Huang SJ, Schatz F, Masch R, Rahman M, Buchwalder L, NivenFairchild T, Tang C, Abrahams VM, Lockwood CJ: Regulation of chemokine production in response to pro-inflammatory cytokines in first trimester decidual cells. J Repdrod Immunol 2006, 72:60-73

33. Lockwood CJ, Yen CF, Basar M, Kayisli UA, Martel M, Buhimschi I, Buhimschi C, Huang SJ, Krikun G, Schatz F: Preeclampsia-related inflammatory cytokines regulate interleukin-6 expression in human decidual cells. Am J Pathol 2008, 172:1571-1579

34. Athanassakis I, Bleackley RC, Paetkau V, Guilbert L, Barr PJ, Wegmann TG: The immunostimulatory effect of $T$ cells and $T$ cell lymphokines on murine fetally derived placental cells. J Immunol 1987, 138:37-44

35. Reister F, Frank HG, Kingdom JC, Heyl W, Kaufmann P, Rath W, Huppertz B: Macrophage-induced apoptosis limits endovascular trophoblast invasion in the uterine wall of preeclamptic women. Lab Invest 2001, 81:1143-1152

36. Renaud SJ, Macdonald-Goodfellow SK, Graham CH: Coordinated regulation of human trophoblast invasiveness by macrophages and interleukin 10. Biol Reprod 2007, 76:448-454

37. Croy BA, Ashkar AA, Minhas K, Greenwood JD: Can murine uterine natural killer cells give insights into the pathogenesis of preeclampsia? J Soc Gynecol Investig 2000, 7:12-20

38. Zhou Y, Damsky CH, Chiu K, Roberts JM, Fisher SJ: Preeclampsia is associated with abnormal expression of adhesion molecules by invasive cytotrophoblasts. J Clin Invest 1993, 91:950-960

39. Takimoto E, Ishida J, Sugiyama F, Horiguchi H, Murakami K, Fukamizu A: Hypertension induced in pregnant mice by placental renin and maternal angiotensinogen. Science 1996, 274:995-998
40. Simon C, Frances A, Lee BY, Mercader A, Huynh T, Remohi J, Polan ML, Pellicer A: Immunohistochemical localization, identification and regulation of the interleukin-1 receptor antagonist in the human endometrium. Hum Reprod 1995, 10:2472-2477

41. Dunn CL, Kelly RW, Critchley HO: Decidualization of the human endometrial stromal cell: an enigmatic transformation. Reprod Biomed Online 2003, 7:151-161

42. Kelly RW, Carr GG, Elliott CL, Tulppala M, Critchley HO: Prostaglandin and cytokine release by trophoblastic villi. Hum Reprod 1995, 10:3289-3292

43. Rothermel CD, Schachter J, Lavrich P, Lipsitz EC, Francus T: Chlamydia trachomatis-induced production of interleukin-1 by human monocytes. Infect Immun 1989, 57:2705-2711

44. Jendro MC, Fingerle F, Deutsch T, Liese A, Kohler L, Kuipers JG, Raum E, Martin M, Zeidler H: Chlamydia trachomatis-infected macrophages induce apoptosis of activated T cells by secretion of tumor necrosis factor-alpha in vitro. Med Microbiol Immunol (Berl) 2004. 193:45-52

45. Chen YC, Wang SY: Activation of terminally differentiated human monocytes/macrophages by dengue virus: productive infection, hierarchical production of innate cytokines and chemokines, and the synergistic effect of lipopolysaccharide. J Virol 2002, 76:9877-9887

46. Sprecher E, Becker Y: Detection of IL-1 beta. TNF-alpha, and IL-6 gene transcription by the polymerase chain reaction in keratinocytes, Langerhans cells and peritoneal exudate cells during infection with herpes simplex virus-1. Arch Virol 1992, 126:253-269

47. Heine RP, Ness RB, Roberts JM: Seroprevalence of antibodies to Chlamydia pneumoniae in women with preeclampsia. Obstet Gynecol 2003, 101:221-226

48. Arechavaleta-Velasco F, Koi H, Strauss JF, 3rd, Parry S: Viral infection of the trophoblast: time to take a serious look at its role in abnormal implantation and placentation? J Reprod Immunol 2002, 55:113-121

49. Kaiser T, Grehan M, Brennecke SP, Moses EK: Association of the TNF2 allele with eclampsia. Gynecol Obstet Invest 2004, 57:204-209

50. Saarela T, Hiltunen M, Helisalmi S, Heinonen S, Laakso M: Tumour necrosis factor-alpha gene haplotype is associated with pre-eclampsia. Mol Hum Reprod 2005, 11:437-440

51. Lachmeijer AM, Nosti-Escanilla MP, Bastiaans EB, Pals G, Sandkuij LA, Kostense PJ, Aarnoudse JG, Crusius JB, Pena AS, Dekker GA Arngrimsson R, ten Kate LP: Linkage and association studies of IL1B and IL1RN gene polymorphisms in preeclampsia. Hypertens Pregnancy 2002, 21:23-38

52. Hung TH, Charnock-Jones DS, Skepper JN, Burton GJ: Secretion of tumor necrosis factor-alpha from human placental tissues induced by hypoxia-reoxygenation causes endothelial cell activation in vitro: a potential mediator of the inflammatory response in preeclampsia. Am J Pathol 2004, 164:1049-1061 